\title{
Syntactic Variation in Nigerian English and Students achievement in english language
}

\author{
OBEKA NGOZI OHAKAMIKE \\ Department of Arts and Social ScienceFaculty of EducationEbonyi State University
}

\begin{abstract}
This paper examined the issue of syntactic variation in Nigerian English as it relates to students achievement in English language. Syntactic variation stems from the fact that no two languages are the same. The concept of Nigerian English was discussed. It was observed that when English language is not the mother tongue of the speakers who use it for communicative purpose, another variety is bound to emerge. Nigerian English has been described as being strikingly different from the standard British English variety. Characteristics of the Nigerian English were analyzed viz-a-viz the Standard British English. It was observed to be full of errors and variants. Students' achievement in English language over the years has been a cause of concern to not only the students' but to the generality of Nigerians. One may blame the failure on the interference of the mother tongue on the target language coupled with the insistence that English language exam should be marked based on the standard British English. Based on the above, one of the recommendations is that English language curriculum should be structured to include areas of syntactic variation in Nigerian English vizaviz the standard British English.
\end{abstract}

\section{INTRODUCTION}

One of the important functions of English language in Nigeria lies in its use as the language of education. By this we refer to it as the language of instruction in educational institutions. It is the official language of Nigerians and makes communication possible among the diverse ethnic groups in the country. Nigeria is a second language user of English language. That is, second after the mother tongue (MT). English as a second language (ESL) is used to refer to a community, which use English as their official language, even though it is not native to them, (Awonusi, 2004).

Consequently, as was the case in Nigeria, English came to be used not only as the language of government but also that of education, commerce and the mass media. Thus, English language occupies a very important position in the history of Nigeria. It is the pivot in which all the facets of the society revolve.

The notion of syntactic variation in Nigerian English is based on the fact that no two languages are the same. According to Quirk and Greenbaum (2000) English language developed from old English to modern English and has continued to change with time. From the geographical angle; what we call British English has variations. They also note that there are numerous varieties of the English language and what we mean by English is a common core or nucleus, which is realized only in the different forms of the language that we actually hear or read. Thus, variations exist even between the British English and the American English. Actually the notion of syntactic deviation in Nigerian English stems from the fact that a wide variety of "Englishes" are spoken in Nigeria and diversity in terms of phonology. Vocabulary and syntax are great, ranging from Pidgin English to a near approximation of standard British English (Gut 2005).

The point is that every human language is subject to change and several factors responsible for this may range from geographical, educational, social and stylistic varieties. Each particular usage exhibits peculiar geographical, social or stylistic variations, which are interrelated in varying degrees. A typical example is that of Nigeria which is made up of many ethnic groups with more than 500 different Languages especially Hausa, Igbo and Yoruba, which are regarded as the major Nigerian languages. Basically, when a language such as English language is removed from its native habitat and placed elsewhere, there is always a tendency to preserve some of the characteristics of the old of the old language and absorb new one.

Similarly, Meierkord (2004) also observes that another form of English emerges when speakers of different varieties interact with each other. When English is not the mother tongue of the speakers who use the language for communication purpose, another variety of the language emerges. Thus, from the geographical angle, varieties of English language have emerged among the many ethnic groups in Nigeria especially Hausa, Igbo and Yoruba. Okoro (2004) observed that geographical varieties do exist in Nigerian English and the level at which they are most manifested is phonology. One can usually tell what part of the country a Nigerian comes from by his accent when he speaks English.

Jowitt (1991) supports this view when he states that the type of English spoken and written by Nigerians varies according to the level of general education attained because there is an obvious correlation 
between the level of educational attainment and the level of proficiency in English. Dadzie (2004) opines that the true character of any language is seen in its syntax and a flagrant departure from its provisions constitutes a violation of its essence. Hence, syntax has to do with not only the word order but the organizational structure of the sentence. Therefore at the syntactic level any misuse will come against the level of international acceptability.

Syntax may also be defined as the arrangement within sentences of grammatical categories and of lexical items as realizations of those categories; According to Jowitt (1991), syntax often deals with the structure, use and meaning as well as the combinatorial properties of such words and so trespasses upon the territory of morphology, lexis and semantics. Therefore, the concept of syntactic variation stems from the fact that no two languages are the same. The geographical, social, educational and other factors make it imperative that Nigerians being a second language user of English must be at variance with standard British English (SBE). By deviation, this paper infers that in certain linguistics context, use is made of an item different in certain respects from the standard item so that the non- standard item is, in a sense, substituted for the standard item. Hence variation embraces both errors and variants.

Poor achievement in English language has been attributed to syntactic variation as observed in Nigerian English by Macarthur (2002) to include such area as the treatment of uncountable nouns as countable nouns plus the omission of determiners before nouns, inappropriate use of prepositions and deviation in the construction of stative verbs and wrong use of tenses. These variations include the pluralization of such standard British English (SBE) uncountable nouns as advice, furniture, equipment, luggage, information, wrong use of determiners and wrong use of prepositions.

\section{ERRORS}

Error is one of the norms of inter language. It is legitimate to speak of variation as error' when they are due to wrong learning, and are generally regarded by educated people as errors. Specifically, some of these errors may be attributed to mother tongue transfer. For example, (I hear the smell of gas), others to false hypothesization or over-generalization (I am go), others, to failure to learn the special phonic or syntactic features of certain words (she deals on cloth). Errors are corrected through comparison with standard forms and usage and the motive for correction comes from a variety of psychological sources such as inability to communicate adequately, censure (often in form of mockery) by peers, elders etc. and the fear of poor achievement in examinations, ( Jowitt, 1991).

Thus the theoretical framework of interlanguage is related to this study because Nigerians are second language learners of English language. One finds out that at the secondary school level, the learners have already mastered their native languages and in the course of learning the target language, which is the standard British English they pass through various linguistic stages, second language learners go through during the process of mastering the target language. They go through the process of overgeneralization, transform of training and apply various strategies in their attempt to communicate in the target language. The learners also transfer some of the rules in the interlanguage system by mixing aspects of their native language to the target language. Hence, the learning process is marked at every state by errors. It is in analyzing the errors students make while acquiring the target language that we can determine the flux of his interlanguage and help him in any pedagogic sense.

\section{THE CONCEPT OF NIGERIAN ENGLISH}

The concept of Nigerian English stems from the fact that no language is the same. For instance, English language developed from old English to modern English and has continued to change with time. From the geographical point of view, what we call British English has variations such as the Liverpool English, Scottish English, Irish English etc. Thus variation even exists between the British English and the America English, (Quirk \& Greenbaum, 2000). Nigerian English can be counted as one of the new Englishes, which have emerged in many parts of the world and have assumed the distinctive characteristics of the various socio cultural environments within which they have evolved, (Jowitt, 1991).

According to Akere (2001), the spoken and written varieties of English in Nigeria more closely reflect the influence of these mother tongue languages. one easily identifies Yoruba, Igbo, Hausa/ Fulani influences in the varieties of English in Nigeria.

According to Dadzie (2004), the standard English has so much in common with the standard British English (SBE) that what differences there are may be described as evidence of variation which is manifested simply because of the differences in location. Omoniyi (2004) maintains that features truly exist in the Nigerian usages at the phonological, lexical, syntactic and semantic levels, which distinguish it from other national varieties like American English, British English and Indian English. According to him, some of these features, however, are not common to all Nigerians. As is the case with other language situations, the more educated users speak a variety that is closer to the acceptable standard than the poorly educated ones who usually use a sub-standard variety. These educational varieties also vary in their degree of intelligibility and acceptability. 
Jowitt (1991) also asserts that the type of English spoken and written by Nigerians varies according to the level of general education attained because there is an obvious correlation between the level of education attainment and the level of proficiency in English. Thus the different Englishes produced by speakers for whom the language is not their first language are understood as being varieties in their own rights. Supporting this view, Meirekord (2004) also states that another form of English emerges when speakers of different varieties interact with each other. When English is neither the mother tongue of the speaker who uses the language for communicative purposes, another variety of the language emerges. Bamgbose (1991) opines that just as English has influenced Nigerian language, so also have these languages influenced English. According to him, aspects of linguistic nativisation include pluralisation of some non-count nouns; introduction of culture specific vocabulary items, back formation, semantic shift, different verb-preposition combinations and some Nigerian Li induced syntactic structures. The most obvious evidence of the linguistic influence of English on Nigerian language is the large number of vocabulary items, which can be traced to loans or loan translations.

Odumuh (1987) states that code-mixing is another major influence of some features that distinguish Nigerian English from other forms of English language in other parts of the world. These he categorizes into lexical, semantic, syntactic and phonological usages at both the spoken and written levels. Using the theory of linguistic variation, he argues that in contact situation- as in the case of Nigeria - a variety of varieties are bound to emerge a form that differs from that of Britain (The English Language model for Nigeria). Ajani (2007) posits that English language has as a result of many years of active use in the Nigerian speech community become part of Nigerian contemporary environment and behavior. It is an artifact whose foreign derived components have in the process of its evolution combined with native Nigerian element to make it local. Hence, Bamgbose 1971, Kachiru 1983, Adeniran 1987, Okoro 2000 agree that truly a legitimate Nigerian English exists. These changes are not only limited to the usual features of transfer of phonological, lexical, syntactic and semantic patterns of Nigerian languages into English but also include the evolution of distinctively Nigerian usages, attitudes and pragmatic use of the language (Bamgbose, 1993).

Basically a Nigerian user of English is a locus of his mother tongue and English (Bilingual and bicultural). His performance in the target language as it were will be conditioned by structural, linguistic as well as socio-cultural interferences, which may be quaint. Such quaintness, Banjo in Adeniran (1987) states can be classified and accounted for as either deviance or variation.

It is interesting to note that both terms indicate a shift from Standard English while deviance is a departure from target norms and constitute error or sub-standard forms which are neither acceptable nor intelligible to both native speakers as well as educated Nigerian users of Standard English. Variation, on the other hand, is a kind of style that is different from the Standard English and includes forms which by all ramifications are correct semantically and syntactically and as such posses a degree of intelligibility and acceptability.

Attah (2000) is convinced that expression such as: more grease to your elbow, my wife has taken in; I search every nook and corners for my missing money. I was late for lecture because of the go-slow on the way; may be non-standard because of the instruction of imprints from the Nigerian cultural and linguistic environment but clearly express the peculiarly Nigerian experience and perspective in ways that do no serious damage to Standard English Structure or general intelligibility. Thus one can usually tell what part of the country a Nigerian comes from by his accent when he speaks English.

\section{SYNTACTIC VARIATIONS}

According to Jowitt (1991), syntax may be defined as "the arrangement within sentences of grammatical categories and of lexical items as realization of those categories. Syntax often deals with the structure, use and meaning as well as with the combinatorial properties of such words and so trespasses upon the territory of morphology, lexis and semantics". This means that syntax includes not only the word order in a sentence but also the internal organization of the words in a sentence, showing how the choice of one item influences another.

On the other hand, deviation deals with the fact that in certain linguistic context differences exist from the standard item and non-standard items are, in a sense substituted for the standard item. Jowitt (1991) explains that variation embraces both errors and variants... An error is a non-standard English form that is unacceptable to a significant number of educated Nigerians while a variant is an idiomatic non Standard English for what is acceptable to and used by most educated Nigerians and is capable of becoming prescribed usage in Nigeria. Examples of variants are the Nigerian use of "Sorry", "brother," "not on seat" "let me land".

Dadzie (2004) states that the true character of any language is seen in its syntax and a flagrant departure from its provisions constitute a violation of its essence. Hence, syntax has to do with not only the word order but the organizational structure of the sentence, therefore at the syntactic level any misuse will come against the level of acceptability. Gut (2005) affirms that Nigerian English (NE) has often been described as strikingly different from Standard English varieties such as British English and American English. One possible 
source of this is the influence of the indigenous tone languages of Nigeria on Nigerian English. Thus, Meierkord (2004) rightly pointed out that transfer from their first languages might characterize the linguistics productions of second language learners.

From within a variationist perspective, however, Benke (1991) inferred that the different Englishes produced by speakers for whom the language is not their first language are understood as being varieties in their own rights and the assumption that learners aim at complete mastery of British English has come to be seriously questioned. Given that a large proportion of non-native speakers' interactions in English do not involve native speakers at all.

Supporting this view, Jowitt (1991) observes that the usage of every Nigerian user is a mixture of standard forms and popular Nigerian English forms, which are in turn composed of errors and variants. Furthermore, Bamgbose (1971) observes that the basic types of error committed by people using English language in Bilingual situations are grammatical and linguistic errors. He explained that both errors are caused by the interference of the mother tongue and pidgin English in the phonological as well as lexical aspects of the language. Thus, the mother tongue has been identified as one of the major problems facing the English teacher as well as the learners. Both at home and outside the classroom, students hardly speak good English and this invariably affects their performance in English language examinations.

Chomsky (1965) observes that, the syntax of any language is governed by rules which are fairly stable and which, unlike the phonology, cut across both horizontally and vertically among the users. That is the rules remain obligatory to the different geographical and social groups using the language, and any instances of violation or misapplication are readily recognizable as such.

Okoro (2004) notes that it is the most unconscious violation of these rules that has consistently yielded deviant expressions of the type that many have unjustifiably labeled Nigerian English rather than as the outright errors that they are. For example such expressions as 'Luggages, equipments, smoothen, Matured person, can be able, some few things, that your friend, it does not worth it, talk less of, you are enjoying, we discussed for a long time, make him to do it, I asked him that are you not coming?' are often all taken for granted as standard Nigerian English usage, whereas each violates one rule of grammar or another. Thus for an expression to be acceptable as standard Nigerian English syntax, it should not violate any rule of English grammar no matter how illogical or subtle. Instances of violation no matter how widespread should be viewed as breaches of the code rather than as characterizing a legitimate variety of the language. For instance, a Nigerian would find nothing wrong with the following expressions: Nigerian English (NE) Standard British EnglishShe was Pregnant for himShe was made pregnant by himI employed a watch night I employed a watchman

On the other hand, It is not unusual for secondary school students to use the unmarked form for the past participle as in: I have kill a snake. Such deviations from the norm are unacceptable syntactic forms. Hence Dadzie (2004) maintains that any structural or syntactic deviance will be considered an aberration and will be unacceptable.

\section{CHARACTERISTICS OF SYNTACTIC VARIATIONS IN NIGERIAN ENGLISH}

According to Jowitt(1991), there are many ways of carrying out a survey of Nigerian English syntax. One could take the grammatical categories of parts of speech one by one and examine the common variations from the standard British English (SBE) that occur in each of these areas or the variations could be assigned into two broad groups-wrong insertions and wrong omission, wrong selection and wrong ordering. Every language works within a system, which is peculiar to it. Second-language speakers of English, like Nigerians, learn the language after acquiring their first, so the natural habit is to learn through the application of logic.

Hence, areas of variations in Nigerian English syntax will be studied using the standard British English as the target model. This could be studied under some of the parts of speech in English language.

Nouns

Variations have been observed in the use of nouns. For instance Dadzie (2004) asserts that in Nigerian English, the general rules of nominal behaviors are followed. However, there are some tendencies, which depart from the norm. Some of these are:

(a) Omission of appropriate article before nouns where they are otherwise mandatory in British English.

NE

SBE

He received award

He received an award.

I have headache.

I have a headache.

It is a rule of the English syntax to use ' $a$ ' before all count nouns whose pronunciation begins with consonant sounds. Similarly, 'an' is also an article which modifies all singular count nouns or article which pronunciation begins with vowel sounds. Other examples where Nigerians omit articles include- get contract, give chance, have bath, make effort, make mistake, take bribe, take excuse, tell lie, tie wrappers, etc. Similarly, the definite article is also omitted where it is expected to be used in SBE, particularly with proper nouns of description as well as names of institutions, newspapers as in

$$
\text { NE: } \quad \text { Principal travelled to village. }
$$


SBE: $\quad$ The Principal travelled to the village.

NE : $\quad$ University magazine is on sale.

SBE: $\quad$ The University magazine is on sale

There are many nouns in everyday use which NE, unlike SBE, treat as countable. These nouns include accommodation, advice, behaviour, blame, chalk, cutlery, damage, equipment, evidence, furniture, grass, information, machinery, money, permission, personnel, staff, stationary, bread etc. Jowitt (1991:112 observes that most of these nouns are

(i) Pluralized by Nigerians (e.g. equipments, machineries etc).

(ii) Preceded in the singular by 'a' or 'an' (an information an evidence etc).

(iii) Preceded in the singular by 'another' instead of 'more' (another money etc).

Also singular words that end with ' $\mathrm{s}$ ' are often preceded by ' $a$ ' in Nigerian English. Examples are a news, a measles, a physics book.

On the other hand, some nouns with plural forms have a tendency to be given singular counterparts in NE for example, such words as pants, scissors, pliers, etc.

Also in SBE the nouns can be made singular by the use of a pair of... as in the pair of scissors is sharp; the pair of trousers is torn.

Wrong classification of Nouns:

A huge number of the errors found in Nigerian English syntax and morphology appear to come under the heading of faulty classification: A word which in SBE belongs to one class is in effect shifted to another class since it is given the syntactic characteristics of that class. The most common type of shift is the reclassification of a noun or an adjective or an adverb as a verb. Common examples of Nigerian English shifts to the verb class include the following: Endings such as - ed are added, the auxiliaries 'do' and 'have' are put in front which results in false verbs. Examples include:
Nigerian English (NE)
Standard British English (SBE)
She backed the baby
She is carrying the baby at her back
He pregnanted her
He made her pregnant
I was not opportune to see you
I don't have the opportunity of seeing you

Wrong Use of Prepositions

Dadzie (2004) observes that the biggest area of uncertainty in Nigerian English usage is prepositions. This is so because of the difference between how English and the local languages express relationships. Similarly, Jowitt and Nnamonu (1985) assert that the chief difficulty for second language learners is to decide which preposition to use before which nouns or noun phrase. The most frequent errors arise from the over-use of 'at', 'on' and 'in'. Examples include the following. $\mathrm{NE}$

She is sitting in the car.

They prefer rice more than beans

She was absent in school

At alert

Asked a favor from me

Leave Aba to Enugu

Congratulate for

SBE

She is sitting on the car.

They prefer rice to beans.

She was absent from school.

On the alert.

Asked a favor of me.

Leave Aba for Enugu

Congratulate on

There is also a tendency to omit the preposition where SBE will insist on it. (c). Prepositionsare also introduced where they are not required in standard British English. Examples are:

NE SBE

The comprises of many systems

The unit comprises many systems

They are advocating for a new library

He emphasized on the importance of rest

They are advocating a new library

He emphasized the importance of rest

Jowitt (1991) posits that the errors contained in list c suggest that a process of false analogy is at work whereby the syntactic characteristics of one class are transferred to a derived word that appears in another. Noun to verb transfer accounts for most of them! E.g . lack as a noun is followed by of in: we suffer from a lack of amenities, discussion derived from discuss is followed by about. An example of verb to verb transfer is comprise of (analogous to consist of) Thus the biggest area of uncertainty in Nigerian English usage is prepositions. This is so because of the difference between how English and the local language express relationships, for instance, A woman is pregnant by a man in SBE but she is pregnant for him in the local languages and this expression has found its way in NE

Other misuse includes the following: NE: in the radio SBE: on the radio; NE: at Lagos/ kano SBE: in Lagos/ Kano 


\section{Wrong use of Verbs}

Verbs of perceiving: in Nigerian languages verbs of

Perceiving appear to be used in the progressive quite freely, and the occurrence of NE forms such as I am seeing: I am hearing you; we are understanding you. The SBE expression of these examples is: I can see; I can hear you; I understood you etc, is probably a reflection of this. NE is also unlike SBE in freely allowing possessive "have" to take the progressive as in Wrong Use of Tenses

Egbe (2004) observes that the most important characteristics of English verbs is that they indicate tenses. Tense deals with the relationship between the action conveyed in the verb and the time it happened. Most secondary school students tend to misuse these tenses. In SBE regular verbs form their past tense forms by adding - ed or $\mathrm{d}$ while we cannot predict the past and past participial forms of irregular verbs from their base forms.

a). Wrong use of irregular verbs:

NE: The news was broadcasted yesterday. SBE: The news was broadcast yesterday.

NE: He casted his vote yesterday SBE: He cast his vote yesterday

Jowitt (1991) observes that the parts of irregular verbs are often wrongly formed (sometimes like 'hit' and split by being classified as regular verbs; while 'grinded' for 'ground' as the past tense and past participle forms of 'grind' is an interesting case of a PNE attempt to make an SBE strong verb weak). Another kind of error in NE can be described as the systemically redundant use of words. An example from Nigerian learners' interlanguage is double marking for the past tense. It may be compared with double marking for the negative in negative verb - forms. Examples 1 didn't know nothing.

It is not unusual to find most students saying:

NE;If he was a woman, he will be pretty. SBE: if he were a woman, he would have been very pretty.

NE: I am having malaria. SBE: I have malaria.

There is also erosion of past participles - $\mathrm{d}$ or 'ed in perfect tenses.

NE: I have just open a bank account.

SBE: I have just opened a bank account.

NE: She has finish cooking

SBE: She has finished cooking.

NE: He use to work in the hospital.

SBE: He used to work in the hospital.

Other inflexional syntactic variations are observed in the use of 'been' and 'being'; 'seen' and 'seeing'. These errors are also due to interference from MT syntax. Similarly the past participle 'en' of some irregular verbs, especially the high frequency 'give' and 'take' may be replaced by - 'ing'. Instead of given and taken, most secondary school students write taking' and giving; having is written as haven'

\section{WRONG ORDERING}

This is another source of syntactic deviation. Displacing words from the positions they occupy in sentences in standard varieties of English in the majority of cases does a lot to hide syntax and meaning. In NE wrong ordering is to be expected. Common among Nigerians is the sequence demonstrative+ possessive + noun, as in 'this our town'. Other sequences of determiners are sometimes wrongly ordered, e.g. - 'other five' in NE while SBE says five others. The rule that requires inversion of subject and auxiliary after 'so' meaning 'also' and after negatives and semi - negative in sentence - initial position is often ignored in NE, so is the rule that requires reversal of inversion after WH - words in indirect speech. Examples

NE: He asked me what was the time

SBE: He asked me what the time was.

Examples of wrong ordering are:

NE: Page what SBE: What page

NE: plate numbers $\quad$ SBE: number plate

McArthur (2002) points out that areas of syntactic variation among learners of English as a second language include a lack of subject - verb agreement in sentences, omission of definite articles before nouns, stative verbs are given progressive forms, a preference for the present perfect over the simple past and the use of the present continuous for past actions.

Schmeid (1991) also observes that speakers from African countries (Zambia, Nigeria and Kenya) and grammatical features of African new Englishes involve among other features - the omission of determiners in front of certain nouns, extension of progressive constructions to stative verbs and variation with regard to verb complementation. On Nigerian English McArthur (2002) further states that areas of variation concentrates largely on noun and verb phrase grammars; the treatment of uncountable nouns as countable nouns; a seemingly reversed usage pattern for definite articles and a particular use of prepositions as specific characteristics of this nativised variety. These are common errors observed among secondary school students. 


\section{ACHIEVEMENT IN ENGLISH LANGUAGE}

The role of English language as a second language in Nigeria cannot be overemphasized. It is not only the language of communication but the language of education. Fakeye (2012) observes that the English

language achievement of the Nigerian student has been on a steady decline over the years. WAEC Chief Examiners $(2002,2003,2004)$ in their reports complained about the inability of the candidates to construct grammatically correct sentences free from errors of agreement between subjects and their verbs. Wrong use of preposition, uncountable nouns are treated as countable, wrong omission of determiners before nouns and wrong use of verbs and tenses were some of the complaints in the list. The students have the tendency of pluralizing uncountable nouns such as information, equipment, machinery and others such as using non standard British English expressions such as big man, watch night, cash madam, well done, not on seat.

Also wrong grammatical expressions were observed in their essays such as still yet, can be able, must have to, more better, lesser, no any. It is also not unusual to hear expressions such as I was opportuned to see my brothers yesterday; I branched to my father's office. I searched every nook and corner for my missing money. Ada was late to school because of the go-slow. There is also the omission of appropriate article where necessary and the addition of -ed to form the past tense of irregular verbs. Most of these students also have difficulty in deciding which prepositions to use before nouns. Student's proficiency in English as measured by WAEC examinations seems to be declining rapidly. However, since these candidates, cannot be classified as being intellectually inefficient one may assume that the causes of these mass failures are to be found in the interference of mother-tongue on the target Language. According to Mohammed (1995), the high failure rate is occasioned largely by the (no longer tenable) decision of WAEC to norm its examinations against the standard of similar examination bodies in the United Kingdom. Commenting on the issue of poor achievement in English language, the WAEC Chief Examiner (2002) reported that the main weakness observed in the scripts of the candidates had to do with lack of familiarity with the required formats, construction of loose sentences, and transliteration from mother tongues (MT) and abuse of the basic rules of grammar. Examples of errors discovered in grammar were

(1) Wrong concord e.g. this days; one of my friend

2. Wrong tense usage, e.g. since we leave school. She have a bag.

3. Wrong constructions

4. Wrong expressions, e.g. there are many people who uses sport to feed themselves.

Omoniyi (2004) observes that at the secondary school, the learners are exposed to all the rules governing the use of the language and he is expected to intuitively construct and operate an Error Free Detective Device (EDD) by which he knows that certain sentences and expressions are well formed and others are not In the exam undue emphasis is placed on mechanical accuracy and expression errors (that is, correct usage) all based on foreign standards.

Hence, the problem of variations in Nigeria English tackled must be tackled if the high failure rate in English language is to be reversed. Moreover, Kujore (1985) blamed the problem of poor achievement in English language among students on the fact that teachers are not sure about what to teach and test. Examples of such areas of variations include the following.

NE: I have filled the application form. SBE: I have filled in the application form.

NE: more grease to you elbow SBE: more power to you elbow.

NE: congratulated him for. SBE: congratulated him on.

NE: can you borrow me your money SBE: can you lend me your money.

These errors are mostly observed in the spoken and written English of secondary school students. Otagburuagu (2002) suggests that English language instruction in Nigeria must recognize the linguistic situation enumerated above and build on the insights from contrastive and error analyses for effectiveness. This challenge demands the identification of the differences between the English language and the indigenous languages, which could pose problems in English language teaching and learning process. These linguistic differences no doubt contribute to poor achievement in English language among secondary school students.

According to Bamgbose (1995), multilingualism brings about a lot of code - switching and code mixing across varieties for intelligibility. This makes the situation more confusing to the teachers, most difficult for the learner and invariably contributes to this poor achievement in English language.

\section{CONCLUSION}

From the foregoing, one would observe that the issue of errors is an imperative to second language users of English language In Nigerian schools students' achievement in English language is viewed purely and wholly from the perspective of errors and deviance rather than from that of varieties and variations. It is these areas of variations, which language teachers penalize as errors that make English language difficult for students, hence the high failure rate in English language exams. However, it must be stated that all departures from a 
given standard model, where they are neither a completely new creation or a mere paraphrase or valid and meaningful reinterpretation are basically or ultimately errors - errors either of analysis or interpretation. If the issue of syntactic variation in Nigerian English language is considered while scoring students' exams, it will no doubt curb the appalling low level of achievement of pupils in the subject at public examinations in . It is clear from the above that until more attention is paid to Nigerian English, students will continue to record a high failure rate in English language.

\section{RECOMMENDATIONS}

Based on the results of this research work, the researcher recommended the following.

1. English language curriculum should be structured by experts to include areas of variation in Nigerian English viz-a-viz the standard British English. Therefore, Nigerian English syntax should be introduced in the language curriculum at the senior secondary here the students are expected to write an external examination with SBE as the target language.

2. There should be a restructuring of textbooks of instruction to reflect the background of the learners and the sociolinguistic factors in language use.

3.. $\quad$ Exchange programmes should be organized for teachers of English whereby students and teachers of English could be sent to Britain for at least a six month course in the United Kingdom to undergo training in the standard British English under qualified native speakers.

4. It would therefore be fundamentally wrong to use the native speaker model of communicative competence as the sole means of evaluating performance in English by Nigeria students, continuing to do so will only worsen their bad performance and high failure rate in the subject.

\section{REFERENCES}

[1] Adeniran, A (1987). On formally characterizing Nigerian English. LARES IX, 85-99

[2] Ajani, T. T. (2007). Is there indeed a Nigerian English? Journal of Humanities \& Social Sciences. 1(1)

[3] Akere, F. (2001). Nigerian English in sociolinguistic perspectives: users, uses and emerging varieties. In A. B. K. Dadzie and S. Awonusi (eds). Nigerian English-Influences and characteristics. (pp. 256-284). Lagos: Concept Publications.

[4] Akere, F. (1995). Language in the curriculum: an assessment of the role of English and other languages in the education delivery process in Nigeria". In A. Bamgbose et al (eds). New Englishes: A West African perspective. Ibadan: Mosuro Publishers and Booksellers

[5] Attah, M. O. (2000). The acceptability of Nigerian English among secondary school teachers in language in education and society. Lagos University of Lagos press PP 152- 154

[6] Awonusi, V. O (2004). Some syntactic characteristics of Nigerian English," in Dadzie A. B. K \& Awonusi S (ed) Nigerian English: Influences and characteristics. Lagos: Concept Publications

[7] Bamgbose, A (1971). English language in Nigeria. The English Language in West Africa ed. J. Spence

[8] Bamgbose, A (1995). English in the Nigeria environment. In A. Bamgbose et al (eds); New Englishes: A West African perspective. Ibadan: Mosuro Publishers and Booksellers PP 9-26

[9] Banjo, A (1995). On Language use and modernity in Nigeria in Owolabi K (ed). Languages in Nigeria. Ibadan: group Publishes PP 177-188

[10] Benke, J (1991). English as a Language of intercultural communication. Berlin: Cornelsen 54-66

[11] Chomsky, N (1965). Aspects of the theory of syntax. Cambridge, Massachusetts M./.T Press

[12] Dadzie, A. B. K (2004). Some syntactic characteristics of Nigerian English, in Dadzie and Awonusi ed, Nigerian English: Influences and Characteristics. Lagos: Concept Publications. PP 231-236

[13] Egbe, D (2004) Internal varieties in Nigerian English in A.B.K. Dadzie and V.O Awonusi (eds). Nigerian English: Influences and characteristics. Lagos: Panat Publishers.

[14] Gut, U (2005) The prosody of Nigerian English; prosodic aspects of standard Nigerian English' Universitat Bielefeld. http:// www. Spectrum. Unni-bielefeld, de/ TAPS/ Gut. htm?

[15] Jowitt, D. \& Nnamonu, S. (1985). Common errors in English. England: Legman Group UK Limited

[16] Jowitt, D (1991). Nigerian English usage: an introduction. Nigerian Language. 107-124

[17] Jowitt, D (1995). Nigeria's national language question: choices and constraints. In New Englishes A. Bamgbose et al (eds): A West African Perspective. Ibadan: Mosuro Publishers

[18] Kachiru, B. (1992). World English”. In language teaching. Camridge: Caribridge university press.

[19] Kujore, O. (1985). English usage: some notable Nigerian variations. Ibadan: Evans Brothers (Nig. Publishers) Ltd.

[20] Kujore, O. (1995). Whose English? In Ayo Bamgbose et al ed, New Englishes: A West African Perspective: Ibadan: Mosuro Publishers and Booksellers PP 367-369

[21] MacArthur, T. (2002). The Oxford Guide to World English. Oxford: Oxford University Press. 
[22] Meierkord, C. (2004). Syntactic Variations Across international English. English Worldwide. 25(1). John Beyanins Publishing Company.

[23] Mohammed, A. (1995). Communicative competence Acquisition in infeliticious learning environment. In Bamgbose A, Banjo A \& Thomas A (eds). The problem with SSS English in Nigeria. Ibadan: Mosuro Publishers PP 139-146

[24] Odumuh, A (1987). Nigerian English (NigE). Zaria: Nigeria Ahmadu Bello University Press Ltd

[25] Odumuh, A (1993). Sociolinguistics and Nigerian English. Ibadan: Sam Bookman

[26] Okoro, O. (2004). The identification of standard Nigerian English in Dadzie A. B. K \& S. Awonusi (eds). Nigerian English: influences and characteristics. Lagos: concept Publication Pp 156-172

[27] Omoniyi, T. Y. (2004) "The Acquisition and use of English in Dadzie A. B. K \& Awonusi S. (eds) op. cit. Pp 100-104

[28] Otagburuagu, E. J. (2002). "English language literacy instruction in Nigeria as a multi-lingual society" on Onukaogu et al ed, Literacy and Reading in Nigeria. 9(1), ICE Ife: RAN Publishers

[29] Quirk, R. \& Greenbaum, S. (2000). A university grammar of English. England: Pearson Education Limited.

[30] Schmied, J (1991). English in Africa: an introduction London: Leyman

[31] WAEC Chief Examiners Report ((2002). English language. West African Examinations council

[32] WAEC Chief Examiners Report (2003-2004). English language. West African Examination Council 